\title{
The Ibero-American Chapter of DoHaD
}

In November of 2014, the first meeting of the Ibero-American DOHaD Chapter (I-A Chapter) took place in Ponta Grossa, Brazil. It was attended by 102 delegates from Argentina, Mexico, Uruguay, Venezuela, Colombia and Chile. At the meeting, 25 papers and 30 posters were presented including a mix of clinical, epidemiological and experimental studies. The focus of the meeting was to disseminate the concept of Developmental Origins of Health and Disease to the Latin-American and Iberian communities of academicians and health workers. The discussions centred around the concept that diseases of later life, such as metabolic syndrome, could be prevented by interventions during the perinatal phase. Readers of the Journal of DOHaD are invited to sample a selection of the publications related to subjects discussed at the first I-A Chapter meeting: from Chile, Krause et al. present 'Pre-gestational overweight in guinea pig sows induces fetal vascular dysfunction and increased rate of large and small fetuses'; from Brazil, Dalle Molle et al. present 'The fetal programming of food preferences: current clinical and experimental evidence', Ferraro et al. introduce 'New challenges beyond nutrition: C-section, air pollution and domestic violence' and Paes et al. present 'Childhood obesity: a (re)programming disease?'; finally, from Argentina, Alderete et al. present 'Beverage intake and obesity in early childhood: evidence from primary health care clients in Northwest'.

As decided in Ponta Grossa, the second meeting of $\mathrm{DOHaD}$ I-A Chapter will be held in São Luis do Maranhão (Northern Brazil very close to the Amazon Rain Forest and Dune Park of Maranhão from 2-4 November 2016). All readers of Journal of $\mathrm{DOHaD}$ and researchers and students interested in $\mathrm{DOHaD}$ concept are welcome. The conference organizers expect 300 delegates from all countries including Latin America, Spain and Portugal. Already confirmed scientists from Canada, United States, Australia and Europe will join colleagues from I-A Chapter in scientific discussions. The meeting will also be used to organize the chapter and enhance the $\mathrm{DOHaD}$ International Society.

The exciting second DOHaD I-A Chapter meeting will soon be open for registration, with a special discount to members of the DOHaD International Society.

Professor Paulo Mathias Laboratory of Secretion Cell Biology Universidade Estadual de Maringá Av. Colombo 5790 87020-900 Maringá Paraná Brazil 